\title{
ОТ ЛИБЕРАЛЬНО-ДЕМОКРАТИЧЕСКОЙ ПОЛИТИКИ РАЗВИТЫХ СТРАН ГЛОБАЛЬНОГО МИРА К ГОСУДАРСТВЕННОМУ УПРАВЛЕНИЮ ЭКОНОМИЧЕСКИМИ И СОЦИАЛЬНЫМИ ПРОЦЕССАМИ: МЕТОДОЛОГИЧЕСКИЕ АСПЕКТЫ
}

\author{
(c) 2021 Сажина Муза Аркадьевна \\ доктор экономических наук, профессор Факультета государственного управления \\ МГУ им. М. В. Ломоносова, Россия, Москва
}

В статье раскрываются методологические аспекты формирования социально-экономической политики государств, которая приходит на смену либеральной демократии и дерегулированию, долгое время воспринимаемых как синонимы свободы и счастья. Показано, что такой свободной и демократической рыночная экономика зарождалась, а её дальнейшее развитие сопровождалось усилением изъянов рыночного механизма (монополия, несовершенная конкуренция, асимметрия информации, которые порождены самой природой рынка), а также циклическим самодвижением рыночной экономики (от кризиса к кризису), усиливая нестабильность (падение роста производства, безработица) - и всё это смягчало государство путём государственного регулирования негативных экономических и социальных процессов.

Выявлено, что результатом такого развития рыночной системы является смешанная экономика, где рыночный механизм и государственное регулирование дополняют друг друга, а государство и бизнес являются партнёрами, объединёнными в одну кооперацию с доверием друг к другу и общими интересами.

Современный период развития рыночной системы усиливает необходимость государственного вмешательства в экономику. Этому способствуют такие факторы, как: развитие инновационной экономики, новые задачи политики развитых стран, политические санкции, пандемия - COVID-19.

Анализ поставленных проблем ведётся на основе научных трудов представителей зарубежной экономической мысли, а также отечественных учёных, занимающихся этими проблемами.

Делается вывод, что сегодня, как никогда, государство должно вмешиваться в жизнь общества, контролировать его экономические и социальные процессы и управлять ими. Государство как институт смешанной экономики координирует, мотивирует и контролирует действия людей для упорядочивания рыночных процессов со справедливой конкуренцией.

Государственному управлению рыночной системы нет альтернативы.

Ключевые слова: рынок; государство; рыночный механизм; свободный рынок; свободная, несовершенная, справедливая конкуренция; либеральная демократия, избяны рыночного механизма; провалы государственного управления, смешанная экономика; эффективный спрос; социализация инвестиций; экономика предложения; инновационная экономика; образование и наука; здравоохранение; политические санкции; задачи национальной политики; пандемия COVID-19; институт государства.

В современном глобальном мире формируется новая парадигма социально-экономической политики государств - государственное управление экономическими и социальными процессами, которые приходят на смену либеральной демократии и чисто рыночной экономики, где либерализм (лат.- свобода), демократия (греч.народ, власть) и рынок долгое время воспринимались миром как синонимы свободы и счастья.

Обе модели механизма управления экономикой развивались и функционировали на основе исторических изменений в самой рыночной системе. Одновременно они разрабатывались разными школами экономической мысли.

Для сравнения этих моделей рассмотрим, прежде всего, их содержание, свойственные им специфические черты.

Либерально-демократическая модель управления рыночной экономикой впервые была сформулирована в период её зарождения и развития основоположником классической школы экономической теории - А.Смитом, как стихийный саморегулируемый механизм функционирования и развития рыночной экономики. 
А. Смит отмечал, что рыночная экономика - это свободная экономика, принципом функционирования которой является «естественная свобода»: Предоставьте людям возможность делать свои дела, дайте делам идти своим чередом. Такая свобода связана с понимание человека как «экономического человека», действия которого в рыночной экономике приводят к естественному порядку [1].

Каждый участник рыночных сделок - эгоucm - он стремится получить пользу. Это естественное свойство человека и фактор общественного прогресса. Поэтому выбор человека должен быть свободным, тогда он достигнет наилучших результатов. В стремлении к получению пользы должно существовать равноправие людей, а государство обязано создавать условия для свободного выбора каждого человека.

Но эгоизм человека - от природы. Значит его цели могут противоречить интересам окружающих людей. И всё же люди сотрудничают друг с другом ради личной выгоды каждого и общего блага. В результате эффективная реализация своего корыстного интереса и будет «естественным порядком».

Таким образом, «естественный порядок» вытекает из человеческой природы, и он естественен. Ограничения личного интереса одного человека личным интересам другого тоже естественно. Поэтому, один эгоист считается с интересом другого эгоиста и наилучшей формой взаимного оказания услуг друг другу является обмен, основанный на разделении труда. Следовательно, «естественный порядок» возникает стихийно, самопроизвольно, в результате массовых действий людей, где каждый человек выступает как «экономический человек».

Стихийный рынок, отмечал А. Смит, это способ взаимодействия производителей и потребителей на основе информации, передающейся через гибкие и свободно устанавливающиеся цены, то есть через децентрализованный и безличностный ценовой сигнал.

Децентрализованный ценовой сигнал - это рассредоточенная по всем рынкам ценовая информация о состояниях на различных рынках. Экономические агенты приспосабливаются и согласовывают решения друг с другом.

Безличностный ценовой сигнал упорядочивает поведение и взаимодействие экономических агентов без их присутствия, без их личного участия. По словам А. Смита, рыночный ценовой сигнал - это невидимая рука рынка, невидимый механизм, который соединяет производителей и потребителей, заставляя их согласовывать их решения [1].

Однако, взаимодействие спроса и предложения может осуществляться только в условиях конкуренции. Конкуренция позволяет координировать деятельность индивидов внутренним образом, избегая насильственного вмешательства. Это - «свободная конкуренция», она обеспечивает всем индивидам полную свободу покупать и продавать товары по любой цене; свободу производить, продавать и покупать всё, что может быть произведено и продано. При этом, доступ к любым отраслям свободен для всех индивидов на равных основаниях. Следовательно, свободная ценовая конкуренция выступает фактором организации производства. Рыночный механизм дисциплинирует участников: покупатели конкурируют с другими покупателями и не могут объединиться против продавцов. Продавцы соперничают с другими продавцами и не могут навязать покупателям свою волю. Значит, ценовая конкуренция выполняет роль движущей силы взаимодействия спроса и предложения.

Следовательно, рынок невидимой рукой направляет эгоистические действия людей на общественно полезный путь. А система конкуренции уравнивает спрос и предложение, обеспечивая общество производством нужных ему товаров.

Но рыночная система ещё и саморегулируется. Если цены выходят за установленные для всех пределы, то конкуренция их оттеснит. Налицо явный парадокс: рынок, высшая точка экономической свободы, является и строжайшим экономическим надсмотрщиком. К нему апеллировать невозможно.

Таким образом, общество конкурирующих, ищущих прибыли людей, обеспечивает материальное богатство через механизм саморегулирующегося рынка. Помешать этому может только вмешательство государства в дела конкуренции и прибыльности. Но любое ограничение стихийного хода и конкуренции сдерживает экономическое развитие. И главная функция государства в этих условиях - обеспечить естественную свободу, основанную на экономической свободе. А само государство должно быть «ночным сторожем» свободной рыночной экономики [1].

Вот такой свободной и благоприятной воспринималась либерально-демократическая ры- 
ночная экономика.

Однако, с развитием её обнаруживались изъяны стихийного рыночного механизма, которые порождены самой природой рынка: ограниченность конкуренции и появление монополий, монопольный рынок и несовершенная конкуренция, асимметрия информации, неспособность производить общественные блага. Являясь неотъемлемой частью стихийного рынка, изъяны не могут быть уничтожены, их можно только смягчить, уменьшить негативные последствия. Сделать это способно государство посредством сознательного воздействия на стихийные рыночные процессы [2].

Но на характер рыночного механизма влияют и изменения в производительных силах, которые на первом этапе развития рыночной экономики были её наиболее революционным элементом.

Стадия крупного машинного производства сопровождалась ростом и расширением производства, ростом прибыли и рентабельности предприятий, увеличением спроса на производимую продукцию. С этим периодом развития рыночной экономики связано появление циклических кризисов и соответственно циклического характера движения рыночных процессов. Цикличность экономического движения - это непрерывные колебания экономики, когда рост производства периодически сменяется спадом, предложение - падением потребительского спроса.

Кризис как главная фаза цикла представляет собой диалектическое единство предела и стимула роста производства. С одной стороны, он вызывает падение цен, сокращение производства и занятости, падение рентабельности. С другой стороны, в кризисе заключены потенциальные возможности дальнейшего развития экономики. При этом, убытки экономики может вызвать не только кризис, но и чрезмерный подъём. Однако, стихийный рыночный механизм позволяет преодолеть образовавшиеся препятствия и идти дальше.

Следовательно, циклическое движение рыночной экономики - это самодвижение от кризиса к подъёму, от роста производства к её новому падению. Но кризисы, вызванные диспропорциональностью между производством и потреблением, межу предложением и спросом, приводят к дестабилизации экономики, к падению экономического роста, увеличению безра- ботицы, снижению жизненного уровня населения. Стабилизировать положение может только государство, воздействую на циклический механизм движения экономики [3].

Первой теоретической разработкой необходимости государственного макроэкономического управления кризисом явилась концепция «эффективного спроса» английского экономиста Дж. Кейнса [4].

Главными факторами экономики Дж. Кейнс считал совокупный спрос, основными компонентами которого являются потребление и инвестиции. Потребление напрямую зависит от дохода, но определяется предельной склонностью к потреблению. Следовательно, с ростом дохода потребление абсолютно увеличивается, но в меньшей степени, чем доход. Инвестиции являются независимой переменной величиной относительно дохода. Но решение об инвестициях принимаются в условиях неопределённости, поэтому неопределёнными и являются изменения дохода. В результате спрос становится неэффективным, то есть неплатёжеспособным.

Стабилизировать положение может государство, оказывая воздействия на объём эффективного (платёжеспособного) спроса через активную экономическую политику. Государство увеличивает совокупный спрос за счёт собственных расходов и стимулирования инвестиций. Особое значение Кейнс придавал инвестициям, которые определяют движение производства и дохода. Активную бюджетную политику Дж. Кейнс называл «социализацией инвестиций», понимая под этим активное финансирование, кредитование частного предпринимательства из государственного бюджета, а также организацию государственных закупок.

Для повышения эффективного спроса за счёт потребления Дж. Кейнс предлагал организацию общественных работ, рост потребления государственных служащих и перераспределение части дохода в пользу малоимущих слоёв населения.

Вспомогательным средством управления кризисом у Дж.Кейнса является кредитноденежная политика, которая влияет на уровень совокупного спроса через ставку процента. Накачивание экономики денежной массой (механизм «дешёвых денег») приводит к понижению ставки процента и повышению привлекательности капиталовложений. Это показывает движение реальной и денежной сфер экономики.

Политика маневрирования фискальными 
и денежными рычагами может совпадать со стихийным движением экономического цикла, удерживая экономику от «перегрева» в фазе подъёма и стимулирую её в случае намечающегося падения производства.

Следовательно, активное воздействие на кризис у Дж. Кейнса имеет своей целью достижение краткосрочной стабилизации экономики при отсутствии инфляции.

Впервые практику государственного регулирования кризисов осуществили США после Великой депрессии в 1930-х гг. Начиная с 1932 г. в бюджете США выделяется особая статья - «Ассигнования на кризисные мероприятия». Государственное регулирование кризиса проводилось по следующим направления:

- Финансирование и субсидирование корпораций, стоящих на грани банкротства;

- Принудительное картелирование предприятий;

- Государственное регулирование кризисного сельского хозяйства;

- Организация общественных работ и выдача пособий по безработицы.

Финансирование кризисных мер осуществлялось через Реконструктивную финансовую корпорацию. Только за период с 1934 г. по 1939 г. на финансирование данных мероприятий было израсходовано 20,68 млрд. долл., в т.ч.: на общественные работы - 8,48 млрд. долл., на пособия безработным - 3,57 млрд. долл., на помощь сельскому хозяйству - 3,12 млрд. долл. [5]

Теория Дж.Кейнса прошла в своём развитии несколько этапов. Особую популярность она получила в послевоенные годы. А в 1950-60 гг. вера в возможность с помощью государства решить острые проблемы экономики утвердилась окончательно. Масштабы государственного регулирования в развитых странах расширились. В результате весь послевоенный период до начала 70-х гг. XX в. вошёл в историю как «Эпоха Кейнса» - смешанной рыночной экономики, где государственное регулирование экономических и социальных процессов взаимодействует со стихийным рыночным механизмом.[6]

Экономическая политика государства развитых стран строилась на кейнсианских рецептах «эффективного спроса». Основными целями экономической политики разных стран были провозглашены: высокие и устойчивые темпы роста экономики, полная занятость, стабильность цен и равновесие платёжного баланса. Это было наилучшее средство стабилизации экономики, но первостепенное значение придавалось ускорению экономического развития стран.

Результаты «политики роста» в 70-е гг. были противоречивыми: наряду с факторами роста экономики назревали сдерживающие его причины, обострились проблемы безработицы, инфляции, платёжного баланса. Это нашло выражение в стагфляционном характере циклических кризисов 1974-1975 гг. и 1980-1982 гг., когда кризисное падение производства и увеличение безработицы сочетались с высоким ростом цен. В свою очередь, стагфляционные кризисы переплелись с инфраструктурными кризисами (энергетическим, сырьевым, продовольственным), что усилило нестабильность рыночной экономики.

Следует отметить, что на состояние рыночной экономики повлиял и такой фактор, как провалы в государственном регулировании. Дело в том, что не только у рыночного механизма есть объективные стихийные изъяны, вытекающие из природы рынка и смягчающиеся воздействием на них государства. Но и государственное управление рыночной экономикой имеет свои провалы, которые связаны с человеческим фактором и имеют осознанный характер. Это вытекает из двух особенностей института государства - механизма функционирования демократического аппарата и посреднического характера деятельности государства (через государственную бюрократию). Случаются и ошибки государственных служащих, связанные с недостаточным уровнем их квалификации. Если государственный аппарат чрезмерно бюрократизирован, то государство превращается в нерегулируемую стихию, которая неспособна управлять обществом.

В этой ситуации на передний план выходит теория дерегулирования экономики, а такие представители неоконсервативной школы, как Ф.Хайек (Англия), М.Аллэ (Франция), М.Фридмэн (США) получили за это Нобелевскую премию.

Государственному вмешательству в экономику неоконсерваторы приписывали все затруднения в развитии рыночной экономики: инфляция, нестабильность, снижение производительности труда, ослабление стимулов к росту и техническому прогрессу. Поэтому они призывают к ориентации на свободное частное предпринимательство и рыночный механизм, к 
ограничению государственного вмешательства в экономику. «За свободный рынок!» - таков главный лозунг неоконсерваторов.

Однако, во второй половине ХХвека рынок уже не был свободным, конкуренцию уже не была совершенной, демократия отличалась властью богатых, олигархии, а государственное вмешательство в экономику, хотя и существовало, но аргументировалось другой необходимостью.

Неоконсерваторы отказываются от макроэкономической методологии кейнсианства. Их исходный пункт - микроэкономические процессы, то есть стимулы и мотивы отдельных фирм. Ограничение деятельности государства связано с перенесения акцента со спроса не предложение, что означает в реальной действительности поощрение свободы частного сектора. Следовательно, государственное регулирование ограничивается рамками интересов крупного частного капитала. На первый план выдвигается задача борьбы с инфляцией и рост эффективности прибыльного функционирования частного капитала в ущерб национальным проблемам и полной занятости. Это направление известно в научной литературе как монетаризм.

Ведущим представителем монетаризма и главным оппонентом кейнсианства является американский учёный Милтон Фридмэн. Его главная заслуга состоит в разработке денежной (монетарной) политики [7].

Рыночное хозяйство, по словам М.Фридмэна, является устойчивым, ибо основано на саморегулировании, когда высокую стабильность обеспечивает конкуренция, а корректировку при нарушении равновесия осуществляют цены. Обеспечить экономическую стабильность помогают денежные факторы государственного регулирования. А поскольку колебания денежных факторов происходят с некоторым разрывом во времени, то денежное государственное регулирование носит долгосрочный характер.

Денежная политика государства, по М.Фридмэну, балансирует между Сциллой (золотой стандарт, действующий автоматически) и Харибдой (группа чиновников, собранная в «Независимый Центральный банк»). Золотой стандарт сейчас невозможен, а произвольная денежная политика центрального банка чревата ошибками. М.Фридмэн делает вывод, что денежной политикой должны управлять не люди, а закон. Органы власти должны ежегодно увеличивать количество денег на хпроцентов (х = 3-5\%). Монетарное правило уравнения обмена: $\mathrm{MV}=\mathrm{PQ}$, то есть количество денег (M) с учётом скорости обращения денег (V) равно ценам (P) умноженным на физический объём товаров и услуг (Q). Поэтому MV = ВНП (результаты производства - валовый национальный продукт), то есть величина ВНП зависит от предложения денег, а скорость обращения денег стабильна.

Следовательно, монетаристы делят экономику на 2 сектора. Реальный сектор - производство и продажа товаров и услуг. Здесь действуют только рыночные силы. Денежный сектор - это сфера деятельности государства. Задача государства - снабдить денежный сектор нужным количеством денег и сделать его нейтральным по отношению к реальному сектору.

Практика консерваторов имела многочисленные внутренние противоречия, поэтому государственная политика давала сбои по всем направлениям. Она помогла экономике выйти из кризиса и снизить темпы инфляции. Но не возрос ВНП, увеличился бюджетный дефицит. В теории и практике наблюдался синтез кейнсианства и монетаризма. А в 90-е гг. наметился возврат к кейнсианству.

Это показывает, что в экономической науке нет бесполезных и ненужный идей. Если в экономике меняются приоритеты экономического развития, то меняются и соотношения рыночных сил и форм государственного регулирования.

В наши дни в глобальном мире формируется новая модель управления экономикой, в которой важное место отводится государству. Государство, а не только рынок, должно управлять экономическими и социальными процессами экономический рост, социальное богатство, демократия должны быть тесно связаны с государством [8].

В основе таких изменений в мире лежат объективные факторы. Прежде всего - это быстрота и радикальность технических сдвигов в инновационной экономике. Это порождает дискомфорт - социально-экономический и политический для разных групп общества: для инвесторов повышается неопределённость отдачи от инвестиций, а для работников - неопределённость рынка труда, сдерживающая потребительский спрос. Оба эти обстоятельства негативно влияют на экономический рост и динамику доходов, вызывая трансформацию политических 
предпочтений и, соответственно, изменение во внутренней политики развитых стран.

Одновременно в экономической теории идёт критика либерализма. Особенно критикуются труды Фр.Хайека [9], М. Фридмэна, их избыточная приверженность рынку, подчёркивается ограниченность «экономики предложения», делается призыв больше внимания уделять «экономике спроса» (Дж. Кейнса).

Ещё один фактор, изменяющий современный механизм управления экономикой развитых стран - это политика государств [8]. В политике развитых стран усиливаются:

- Роль национальной повестки по сравнению с глобальной;

- Рост внимания к вопросам национальной безопасности;

- Роль политических процессов по отношению к экономике;

- Экономическая конкуренция заменяется политической.

Большое внимание на механизм управления экономикой развитых стран оказывают сегодня политические и экономические санкции. Особенно это касается России [10].

Основной целью экономических санкций является принуждение правительства санкционированного государства изменить свою политику. Применительно к России они выступают в двух формах: торговые налагаются на импорт из России и на экспорт в Россию, финансовые санкции - это отмена или задержка выдачи кредитов или грантов.

Ключевым направлением государственной борьбы с санкциями в России явились поддержка государством импортозамещения и экспорта несырьевых товаров, а также содействие развитию малого и среднего бизнеса и обеспечение социальной стабильности. Привлечение инвестиций за счёт иностранного капитала западного происхождения Россия заменила странами-членами БРИКС. Ближайшая задача России - поставлять за рубеж переработанную продукцию с высокой добавленной стоимостью.

Важнейшей задачей государства в условиях политических санкций - укреплять доверие между властью и бизнесом. Это достигается обеспечением свободы предпринимательства как ответ России на санкции западных стран. Сегодня набирает обороты новая модель взаимодействия государства и бизнеса. Государство, как и бизнес, становится и предпринимателем, и бан- киром, и работодателем. Совместно с бизнесом государство способствует развитию экономики. Но у государства в таком партнёрстве есть и своя функция - добиться катализации рыночного механизма, снизить цены на внутреннем рынке при растущем уровне доходов населения путём создания здоровой конкуренции в неконкурентной среде. Следовательно, в новой модели взаимодействия государства и бизнеса все участники интегрированы в единую кооперацию. А координатором и управителем всех процессов выступает государство [8]. Таким образом, экономические санкции - это «палка о двух концах». Этой палкой можно нанести удар не только по стране-объекту санкций, но и по самим организаторам санкций, а главное - санкции стимулируют экономическое развитие стран, против которых они направлены.

Фактором, влияющим на необходимость усиления государственного регулирования рыночной экономики, является сегодня развивающаяся пандемия COVID-19. Подобно экономическому кризису, пандемия характеризуется падением промышленного производства, доходов граждан, ростом безработицы, бедности и государственных расходов. В 2020 году темпы прироста мирового ВВП можно считать худшими со времён Второй мировой войны. По прогнозу ОЭСР падение его составило 4,2\% [13].

Кризисные проблемы в реальной экономике выразились в следующем: во-первых, серьёзно обострилась проблема коммуникаций [11]. Люди были вынуждены в сжатые сроки трансформировать многие процессы и процедуры, переведя их в удалённый электронный формат или минимизировать своё физическое участие в них. В условиях экстренного перехода на электронные средства коммуникаций были снижены стандарты безопасности, имеющие дело с коммерческой или государственной тайной. Сама электронная форма коммуникаций влечёт невидимые, но явные при реализации издержки снижение межличностного доверия как одного из ключевых факторов предпринимательской деятельности. Во-вторых, в кризисных условиях система здравоохранения вынуждена перепрофилировать имеющиеся медицинские центры и больницы для решения первостепенных задач борьбы с пандемией, что порождает негативные последствия как для врачей, так и для пациентов. Вместе с тем, не снимается проблема медицинского обеспечения лечения других болезней. 
Есть недолеченные болезни или приобретённые вследствие недостатка медицинского обслуживания. Это является причиной нехватки коек, лекарств, врачей, а также чрезмерной зависимости от импорта лекарств [14]. В-третьих, заявила о себе проблема образования. Формат заочного обучения пришлось вводить в экстренном порядке, применять для миллионов обучающихся по самым разнообразным специальностям. В итоге, проблемы электронного формата коммуникаций усилились. Существенное ослабление контакта учителя и учеников приводит к значительному ухудшению освоения преподаваемого материала - ослаблена концентрация большинства учащихся, существенно сужен круг средств, доступных учителю для преподавания или контроля. Кроме того, не все знания поддаются кодификации. Всё это говорит о том, что в долгосрочном периоде массовое онлайн-образование скажется негативно на знаниях обучающихся и снизит их ценность как работников. И это сдерживает интеграцию образования с наукой [12].

В целом, нужно отметить, что основной удар пандемии пришёлся на человеческий капитал ключевой ресурс инновационной экономики. В условиях пандемии люди ограничены в возможности накапливать и реализовать свои знания, навыки и умения, а также формировать тесные связи, основанные на личном знакомстве. Новые технологии инновационной экономики будут направлены на достижение нового качества коммуникаций, в чём и заключается успех инновационного процесса [11].

Для повышения качества новых технологий, эффективного их использования, для экономического роста и вовлечения широких слоёв общества в получении выгод от новых технологий нужна государственная поддержка. Хотя государственное регулирование не должно подавлять рыночные механизмы. Государство должно быть сознательной и «дешёвой» (по А. Смиту) структурой, управляющей гражданским обществом во благо его граждан [2].

Форма протекания вирусного кризиса значительно отличается в разных странах мира в зависимости от масштаба его распространения, силы и продолжительности эпидемии. Да и объём применяемых мер и видов государственной поддержки национальной экономики разнится по странам. В этой связи поставлена под сомнение перспектива развития глобализации - стабильное сохранение информационных и ми- грационных потоков. Решающую роль сегодня играют национальные государственные меры восстановления экономики, в т.ч. развитие национальной инновационной системы [11].

На современное инновационное обновление экономики влияет целый комплекс мер:

- Кооперационные связи между производителями и потребителями знаний, услуг, товаров, между реальным сектором и организациями высшего образования и науки для решения проблем кадрового обеспечения, обмена наработанным опытом;

- Ориентир науки на потребности национальной экономики, а не на тенденции глобальных изменений;

- Возникновение новых рынков, выпускающих процесс технологического обновления продуктов и услуг и сокращающих жизненный цикл инноваций.

Поэтому только институциональные реформы, создавая нормативную базу рыночной экономики, институты права, способы информации, консалтинга и экспертизы, а также квалифицированный аппарат управления и контроля могут гарантировать экономическую, социальную и правовую эффективность всего общества. А институт государства, как сознательный регулятор гражданского общества направит эти преобразования на удовлетворение интересов всех граждан [8].

Таким образом, сегодня как никогда, государство должно вмешиваться в жизнь общества, контролировать его экономические и социальные процессы и управлять ими. Значит, экономика является смешанной. Она управляется не только рынком, но и государством.

Либеральной, свободной, рыночной экономике приходит на смену управленческая экономика, где экономический рост, социальное богатство, демократия связаны с государством. Государственному управлению обществом нет альтернативы.

\section{Заключение}

Рынок - высшая точка экономической свободы. Он является и строжайшим экономическим надсмотрщиком - апеллировать к нему невозможно. Государство должно быть «ночным сторожем» свободной рыночной экономики.

Выбор между рынком и государством всегда является выбором между различными типами несовершенства. Неэффективность одного из элементов рыночного механизма не означает 
автоматической эффективности другого элемента.

В смешанной рыночной экономике государство как институт контролирует, корректирует, стимулирует те или иные процессы рыночной экономики и запрещает или ограничивает действия людей с нежелательным результатом. Координация, мотивация и контроль действий людей государством в смешанной рыночной экономике упорядочивает рыночные процессы со справедливой конкуренцией.

В экономической науке нет бесполезных и ненужных идей. Если в экономике не происходит революций, то по крайней мере меняются приоритеты экономического развития, а значит соотношения рыночных сил и форм государственного управления.

\section{Библиографический список}

1. Смит А. Исследования о природе и причинах богатства народов. М.: ЭКСМО, 2016.

2. Сажина М. А. Изъяны рыночного механизма и провалы государственного управления: методологические аспекты. Экономические стратегии, № 8. 2019.

3. Сажина М. А. Управление кризисом. М. ИД «ФОРУМ»-ИНФРА-М. 2012.

4. Кейнс Дж. Общая теория занятости, процента и денег. М.: ЭКСМО, 2007.

5. The budget of the United Government. 1938

6. Сажина М. А. Научные основы экономической политики государства (Экономическая мысль) М. ИД «ФОРУМ» - ИНФРА-М. 2018.

7. Фридмэн М. Количественная теория денег. М. 1966.

8. Сажина М. А. Управленческая экономика. М.: ИД «ФОРУМ»-ИНФРА-М. 2016.

9. Хайек Ф. Пагубная самонадеянность. М. Новости. 1962.

10. Сажина М. А. Экономический кризис как следствие политических и экономических санкций против России и пути выхода из него. Вестник международного института менеджмента. ЛИнК, №3, 2016.

11. Инновационная экономика. М.: ИД «ФОРУМ»-ИНФРА-М. 2014.

12. Кохберг Л. М. Наука и образование в России: пути интеграции. Вестник финансовой академии. № 1, № 2 . 2006.

13. Continued fiscal support and public health action needed to make hope of recovery a reality. Режим доступа: http://www.oecd.org/newsroom/continued-fiscal-support-and-public-health-action-needed-to-make-hope-ofrecovery-a-reality.htm (15.12.2020)

14. Аналитический обзор Национального рейтингового агентства «Фармацевтический рынок РФ - государство нам поможет?» (июль 2020). Режим доступа: https://www.ra-national.ru/sites/default/files/Report\%20 NRA\%20Pharma\%20August\%202020.pdf (08.01.2021) 